\title{
Winners and losers, dollars and sense
}

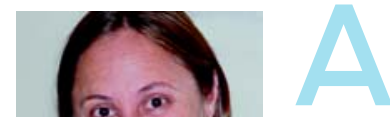

we write, Australians have recently invested more than A $\$ 400$ million in wagers on "the race that stops a nation", while the United States has held a US\$6 billion election in which one of the central issues was the cost of health care. It seems like an ideal time to think about picking winners and counting costs.

To pick winners in health care, it makes sense to weed out the poor performers. Internationally, there has been a groundswell of activity seeking to identify and reduce the use of health care interventions that deliver marginal benefit, say Elshaug and colleagues (page 556). As part of an Australian evaluation project, they conducted a pragmatic study that flagged over 150 Medicare Benefits Schedule (MBS)-funded health care practices as potentially unsafe, ineffective or otherwise inappropriately applied. In a linked editorial (page 538), Scott says that opinion about the value of some of the identified items will be divided and that the next steps must involve Australian specialist colleges, as is happening in the doctor-led US "Choosing Wisely" campaign (JAMA 2012; 307: 1801-1802).

The "appropriateness" of the care provided in Australian health care settings was the subject of the CareTrack study, published earlier this year (MJA 2012; 197: 100-105).

Ruth Armstrong Senior Deputy Editor

mja@mja.com.au

doi: 10.5694/mjal2.c1119 Understandably, many commentators greeted the main finding (that $57 \%$ of eligible health care encounters met the appropriateness standards defined by the researchers) with dismay, but arguably the study was as much about identifying health care winners as losers. As two of the authors wrote elsewhere at the time: "For the first time, nationwide research has identified where we are getting it right and, similarly, where we are falling short. That means we can now begin to recalibrate our healthcare system to achieve better results, both for patients and for administrators charged with stretching our health dollars further" (http://www.abc.net.au/unleashed/4136128.html).

There are bound to be pitfalls in picking winners and losers. The CareTrack study assessed compliance with published guidelines and expert opinion in a limited number of encounters and was not able to take into account many of the complexities of practice or clinical outcomes. Contributors to this issue's Matters Arising raise these and other concerns (page 548), with the CareTrack authors welcoming the ongoing debate.

When it comes to counting costs, Fransen and colleagues (page 565) confirm that non-melanoma skin cancer is Australia's most expensive cancer and is likely to remain so for the near future. In 2010, the total MBS benefit for its treatment was A $\$ 93.5$ million, and is estimated to increase to A \$109.8 million in 2015. They anticipate that this growth will slow in the future, as decades of public health campaigning pave the way to a sun-smarter generation. This week is Skin Cancer Action Week (18-24 November).

Another public health winner in Australia is tobacco control. In an editorial, Daube and colleagues (page 537) celebrate the successful campaign to relegate cigarettes to plain "nappy-brown" packaging from 1 December 2012. They also remind us of the high price we are paying globally for smoking - five million deaths per year at an estimated profit for tobacco companies of US\$6000 per death.

When picking winners and counting costs in health and health care, we would do well to take the advice of the winner of the medical practitioner category of the MJA, MDA National, Nossal Global Health Prize. Drawing on a range of stark contrasts between her encounters with patients in Australia and overseas, Srivastava (page 582) argues for the rich-world-poor-world medicine divide to be more than just a narrative. She points out that, despite crying poor, our health care system is anything but - " I assume this is why we can casually discard half-empty vials of the most precious drugs" - and encourages all doctors to think about the effect of their individual clinical practice on global, as well as local, health resources.

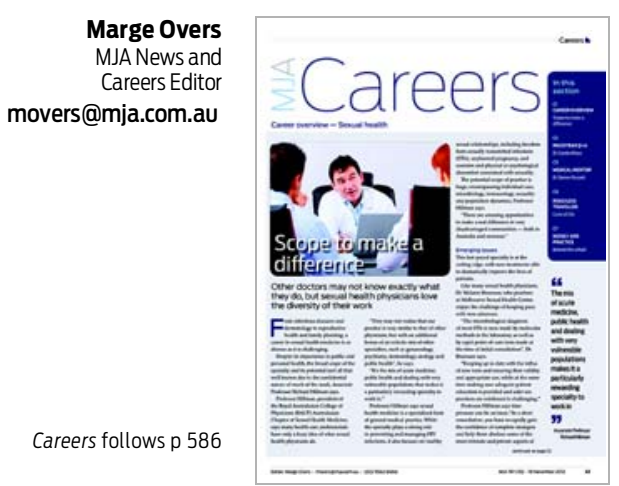

\section{Quiet achievers}

Sexual health may be one of the most diverse specialties, but it's also one of the least well recognised. Sexual health physicians who describe their role in this issue's Career Overview (page C1) say other doctors only have a vague idea of what they do because of the confidential nature of their work. Yet it is a rewarding specialty at the cutting edge of medical science, says Dr Darren Russell, who traces his career in
HIV medicine in Medical Mentor (page C5). In Road Less Travelled (page C6), we meet Dr Ben Ewald, who travels most roads on the back of a bike, and is an advocate for the health and environmental benefits of cycling. Finally, Money and Practice (page C7) navigates the finances of car ownership, including a light-hearted look at what types of cars various specialists prefer to drive. 